\title{
MicroscopyPioneers
}

\section{Pioneers in Optics: John S. Billings}

\section{Eric Clark}

From the website Molecular Expressions created by the late Michael Davidson and now maintained by Eric Clark, National Magnetic Field Laboratory, Florida State University, Tallahassee, FL 32306

eclark@magnet.fsu.edu

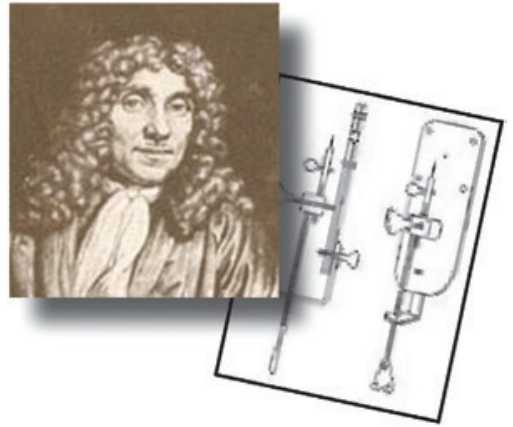

John S. Billings

(1838-1913)

Lieutenant Colonel John S. Billings served as the curator for the United States Army Medical Museum for a tenyear period from 1883 until 1893. During that time, he initiated the assembly of what has become one of the world's largest collections of microscopes. This collection was begun in 1874 by Colonel Billings's predecessor, Lieutenant Colonel George A. Otis, an Army medical officer who

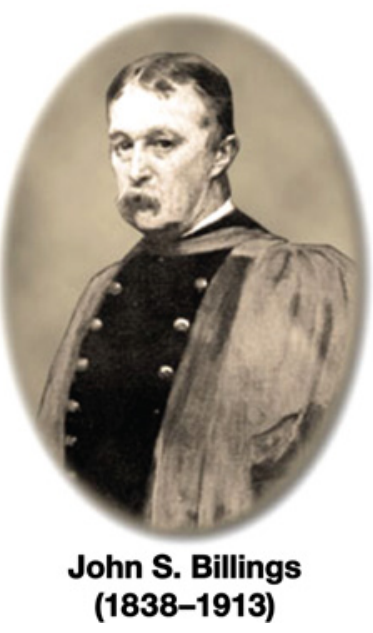

acquired several historic microscopes from a Philadelphia instrument maker.

In 1864, late in the Civil War, Colonel Billings was assigned to organize medical records of the Union Army, and he was placed in charge of the Surgeon General's Office Library in 1865. His efforts in this endeavor eventually led to one of the nation's finest medical resources, the National Library of Medicine in Washington DC.

During the 1880s, as curator of the Medical Museum, Billings served as vice president of the National Board of Health and acted as an advisor on hospital construction, a job for which he was considered an expert. During one of his many trips to Europe in search of books and historic medical equipment, Colonel Billings enlisted the help of John Mayall, Jr., a well-known microscope collector and member of the Royal Microscopical Society, to help procure representative microscopes for the Army's collection.

Colonel Billings received the first shipment of 17 microscopes from Mayall in October 1884, followed by eight very rare microscopes in 1886, and three early Italian models in 1887. By 1888, Mayall had purchased over 140 microscopes for Colonel Billings, who was himself searching throughout Europe for antique instruments.
These efforts inspired many American collectors to contribute to the growing museum collection, and Colonel Billings continued to assist in growing the collection until his death in 1913.

Today, the collection houses over 600 microscopes, many of which are very rare and valuable. Army museum curators have now termed these microscopes The Billings Microscope Collection, and a book has been written that illustrates and describes the microscopes.

Visitors to Washington DC can view many of the microscopes in the Billings Collection at the National Museum of Health and Medicine at Walter Reed Army Hospital.

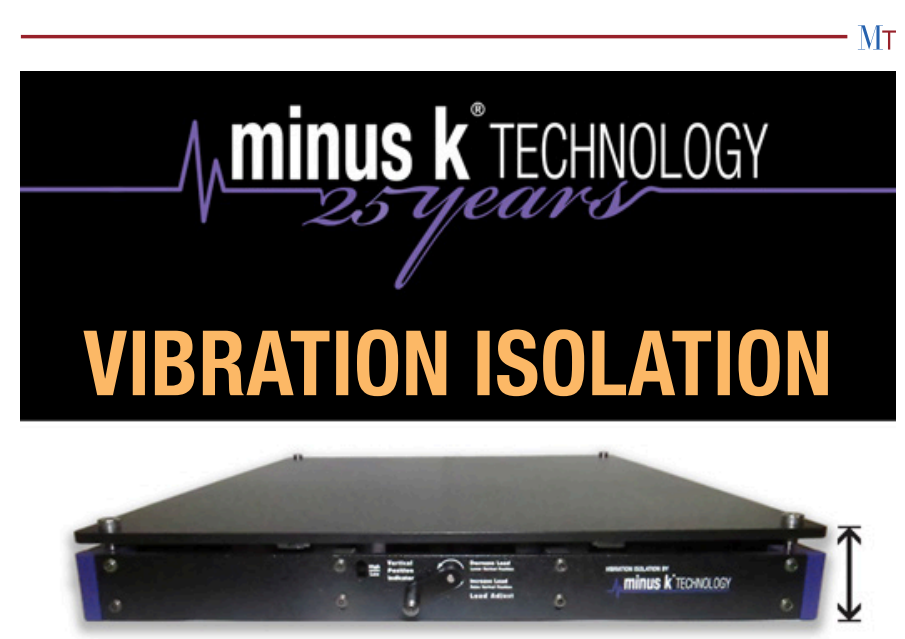

Now only $21 / 4$ inches tall

\section{BREAKTHROUGH}

Ultimate $0.5 \mathrm{~Hz}$ Performance!

Perfect for Microscopes

No Air! No Electricity! www.minusk.com 


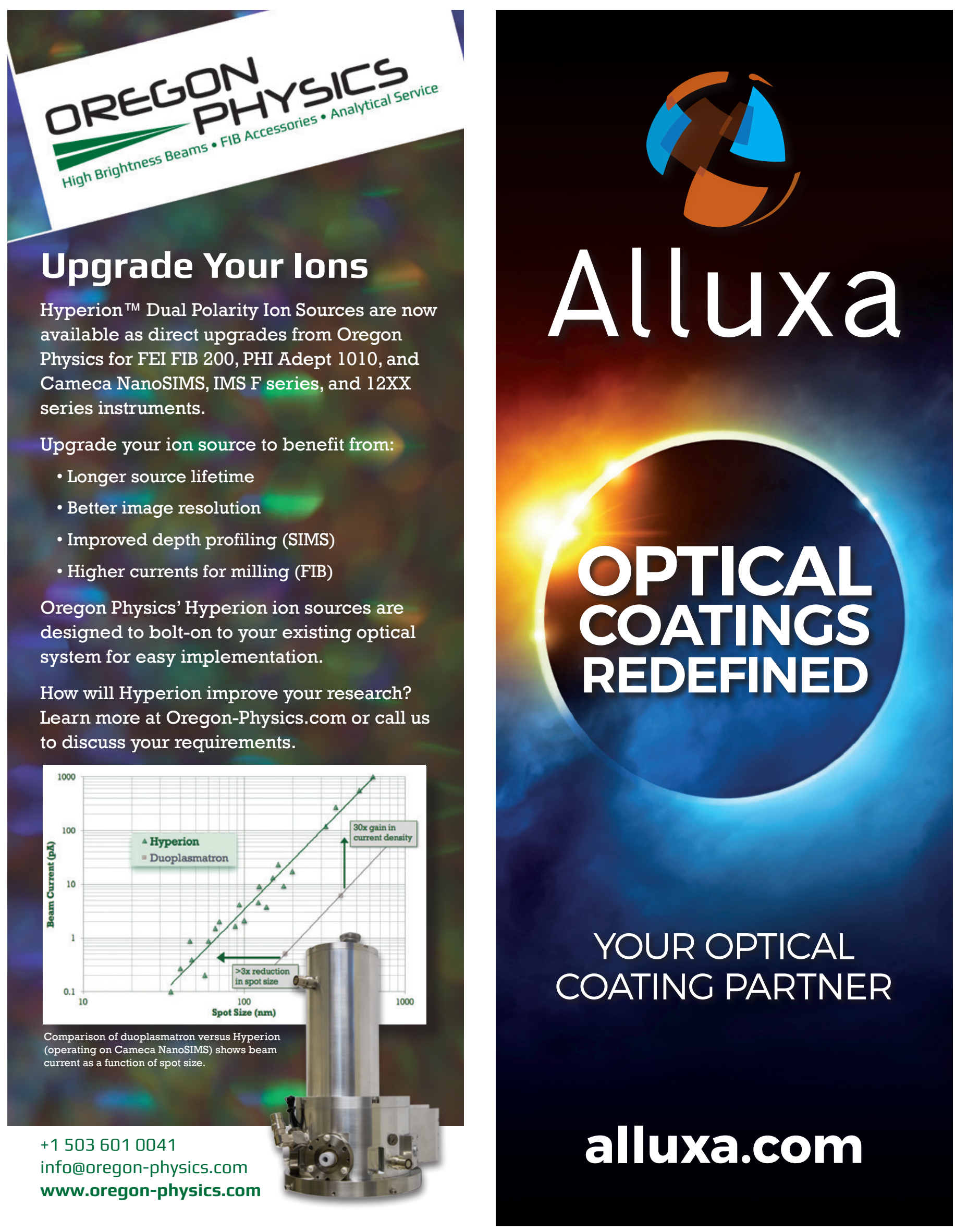

